\title{
Mujeres con daño
}

\section{Reseña a libro: Castillo, Alejandra. Nudos feministas: política, filosofía, democracia, Santiago, Palinodia, 2011, 108 págs.}

Jorge Díaz Fuentes?

Existe una premisa fundamental para entender la política y la práctica de los feminismos, esto es, que nada existe nunca en línea recta. El camino al que nos invita el feminismo, en todas sus posiciones de sentido y en toda su capacidad de producción política es a desconfiar de la idea plana que el tiempo, la historia y los sujetos están escritos en línea recta. Por lo contrario, la práctica del feminismo comprende que las posiciones son siempre más sinuosas, más caóticas o más anarquistas. Con mayores nudos, como un quipu, en el que a pesar de existir miles de nudos hay ahí un lenguaje y un conocimiento a descrifrar. Algo así es el feminismo.

Gran parte del pensamiento de las ciencias giró por mucho tiempo en torno a la idea de linealidad. Entre un momento y otro, entre un tiempo y su futuro existía la idea que para alcanzar a comprender los fenómenos de lo vivo, siempre avanzamos hacia adelante en línea recta: el hombre es la escala de la evolución, una macromolécula es solo la suma de sus unidades estructurales, un gen es la expresión de un comportamiento, una enfermedad es un fármaco. Nada más erróneo, nada más cegado que las miradas planas que buscan encontrar un solo lugar donde existir, una sola disciplina que habitar.

El biólogo decimonónico George Couvier hablaba que continuamente estamos pisando un terreno sobre la base de una catástrofe, donde las especies existentes en el hoy son el producto de un reemplazo por creación sucesiva luego del desastre que lo aniquila todo. Nunca existen los mismos luego de la catástrofe. Algo se crea repetida y sucesivamente luego de la ruina. Sin embargo, catastrofismo y creacionismo son dos visiones que sin duda siguen con la idea de lo lineal, de lo que solo avanza para adelante como cuando solemos pensar la política como una cuestión de mirada y tiempo: nos

Fecha de recepción: 22 de mayo de 2013

Fecha de aprobación: 9 de septiembre de 2014

1 Investigador transdisciplinar de la Disidencia Sexual, Biólogo (Pontificia Universidad Católica de Chile), candidato a Doctor en Bioquímica (Universidad de Chile). Es miembro del Colectivo Universitario de Disidencia Sexual (CUDS) desde el año 2008. Ha escrito textos sobre fármaco-política, cine, teoría y estética feminista participando en ponencias y encuentros de arte y política sexual nacional e internacional. 
dicen siempre que miremos hacia adelante, que tenemos que levantar los ojos para imaginar un mejor futuro. Mirar hacia adelante, no mirar hacia atrás.

El libro de Alejandra Castillo, Nudos feministas: Política, filosofía, democracia nos implica a desvalorar esos imaginarios flanqueados por un solo eje de sentido y para ello interrumpe la dinámica rectilínea con un trabajo desde el feminismo. A esa línea, "ella"le hace "nudos".

Los "nudos", como esas construcciones que parecieran ponen una señal de finalización, pero que quizás lo que hacen es darnos cuenta de un cierto problema, incomodidad o negatividad con la política feminista y su representación de la mujer en el espacio de lo público, en la democracia. "Hay un problema, una incomodidad quizás entre las mujeres, los derechos humanos y la idea de ciudadanía que le es propia" (Castillo: 2011a, 47) dice Alejandra Castillo, insistiendo en una extrañeza al recorrer un territorio que siéndole propio no le es seguro, por donde uno no puede caminar firme. "Nudos" ha sido una imagen que recorre los discursos de los feminismos en Chile, imagen y representación utilizada, citada y vuelta a citar desde que la feminista chilena Julieta Kirkwood visualizara así la política de mujeres, sin la novedad del poner en escena un significante ya asociado a una lógica que intenta comprender una topología de geometrías inalterables. Kirkwood sitúa esa imagen -los "nudos"- en las formas de organización de las prácticas feministas y su relación con el poder, el saber y la representación. Así pues Julieta Kirkwood dice:

Los nudos más recurrentes y perceptibles han tenido que ver (. . .) con el conocimiento, con la relación entre feministas y políticas, con el poder, con la relación femenino/ feminista; con la cuestión de las estrategias, con la idea de profundización feminista versus la amplitud de llegada de la misma acción; con opciones entre vanguardias y masas, con el encierro en lo personalístico versus un planteo feminista social; nudos entre partidos y movimientos autónomos. Y el gran nudo síntesis, por supuesto, el de clase/género (Kirkwood: 1990, 238-239).

La potencia de las imágenes que nos muestran a la vez movilidad y relación nos permiten traducir los esquemas visuales de un tiempo particular y su entrecruzamiento político y social, pero también nos permiten establecer marcos de lecturas abiertos a ser disgregados por restricciones múltiples y no protocolizadas donde incluir miradas sospechosas del canon.

Julieta Kirkwood y Alejandra Castillo en este libro son dos sospechosas tensadas en un mismo espacio, pero en dinámicas temporales diferidas, digámoslo así. Sospechosas del feminismo, sospechosas de la mirada, del ojo. De dos ojos. De su propio ojo y del ojo del feminismo que las mira extraño. Muchas veces con desconfianza. Como también podríamos decir de cierta academia de "autores masculinos que cultivan literariamente su metáfora sin que ellos como sujetos se sientan mínimamente obligados a establecer algún compromiso práctico con las mujeres reales de la lucha política y con la acción teórica del feminismo" (Richard: 2008, 52). 
Si para Julieta Kirkwood el problema está en los "nudos" me atrevería a afirmar-en el repaso de los capítulos del libro- que para Alejandra Castillo un "nudo" no puede hacerse, no puede comprenderse, sino en relación con las dinámicas del "daño". De un daño somático que atañe al cuerpo de las mujeres como marca de su constitución. Pero también como un "daño" simbólico. Un daño en lo político.

Así, en relación con ciertas preguntas planteadas por su autora, el problema no estaría en verificar este "daño", de poseerlo y agenciarlo como estrategia política, sino más bien en la insistencia de aquel remedio que lo cure completamente, promoviendo así una invisibilización. Castillo lo verifica en "una política remedial de género que tiene por objetivo principal asegurar a las 'mujeres' el hecho de ser 'mujeres' sin daño" (Castillo: 2011b, 14).

La insistencia de la posibilidad de dañar la política de la acción afirmativa del feminismo, esa política de solo "mujeres", quizás se encuentre en adentrarse a intervenir los mismos modos de comprensión de las identidades que este feminismo ha sabido excluir, utilizando muchas veces las estrategias de la paridad y la justicia como utopía democrática, un tema ampliamente abordado en el capítulo "El escenario Bachelet y las políticas de la presencia".

De esta forma, y siguiendo los argumentos del libro, ese "daño" que la política rechaza al esperar de nosotros sujetos claros, sanos y coherentes no estaría en la mera inclusión de identidades que resguarden su nicho de derechos y complicidades, donde se encuentren cada uno en sus particularidades, dentro de un marco más amplio y pluralista.

Los posicionamientos críticos desde donde uno actúa deben cuestionar el estatuto global de la sexualidad y su engranaje cultural y no solo aquietarse con su parcela de derechos conseguidos. Porque podríamos caer en un discurso que vuelve a naturalizar las identidades como un catálogo, sin preocuparse por la representación.

Puesto que es esta "batalla por la representación" lo que nos permite comprender que ciertos discursos de lo "natural" no son sino ordenamientos sociales, que de la mano del poder (gubernamental, psíquico, cotidiano) y la violencia (patriarcal, heterosexual y simbólica) construyen un tejido muy finamente organizado que pareciera muy difícil "desdiferenciar" para adentrarse en algunas de sus capas. Una historia tan bien contada que a muy pocos urge exaltar o comprometer.

Ahora bien, Alejandra Castillo en el capítulo "El feminismo no es un humanismo" nos recuerda que las estrategias de representación del feminismo contemporáneo han recurrido a la idea de lo fragmentario como contraposición a lo "unitario", anudándose así a las figuraciones de lo "impolítico". Lo "impolítico" como materialización de una figura, más que hablar desde el seno de la política misma, se enuncia desde los bordes para descalcificar el armazón identitario de la política moderna. Pues, como bien dice:

"estas nominaciones, como nominaciones de lo impolítico, no tienen como preocupación central la dilatación de la dimensión del individuo y de la comunidad hasta 
sus últimos términos (...) No es, en definitiva, como se podría pensar, la comunidad la que comprende dentro de síal individuo, sino el propio individuo el que lleva dentro de síuna comunidad rota" (Castillo: 2011c, 105).

Si las políticas de la interrupción que cuestionan finalmente el patrón moderno de la política lo han hecho por medio de las estrategias de la ficción, del trabajo de pensar mundos posibles e inapropiables que el lenguaje de la universalidad humanista decreta como menos "real" o menos "efectivo", deberíamos entonces cuestionar también las formas que adquieren nuestros cuerpos para desaprender sin melancolía, la morfología actual de nuestras identidades "dañándolas", pues como dice el filósofo chileno Willy Thayer:

Nada se pierde con perder la identidad. No contiene más que un torrente estrecho de necesidades sin pausa, policías y cuidados sin cuento. Lo que en ella interesa, se encuentra en cualquiera. Su perpetuación es la rigidez inmutable, la invarianza que es la ausencia de felicidad. Su cesación es un alivio para la fuerza que la mantiene (Thayer: 2011, 39).

Un proceso de subjetivación sería entonces un desnudo de la clasificación, de la disciplina que creemos dominar, de la mirada con que nos miran y nos miramos.

Ahí podría quizás encontrarse el "daño" particular de una política feminista que se vuelve incómoda y también comprometida con la alteridad desde las figuras de un activismo híbrido entre lo teórico y ficcional, que sepa comprender la configuración del espacio común como una figuración múltiple y no clausurada. Un "daño" que cierto feminismo de la acción afirmativa insiste en excluir, pero que no es sino necesario para comprendernos como sujetos siempre incompletos con una difícil filiación que anuda nuestros cuerpos al feminismo con figuras que como nos dice Alejandra Castillo.

"parecen hablarnos de lo "absolutamente otro" de lo venido de un lugar aún no descifrado, talvez de un más allá de lo humano. Figuras de la alteridad que de antaño, como sabemos, han estado presentes a la hora de describir a las mujeres" (Castillo: 1998,72).

Así recibo la provocación que Nudos feministas: Política, filosofía, democracia nos invita mediante sus reflexiones sobre lo político y lo impolítico del feminismo, como territorio de disputa entre lo representado y lo que queda fuera de campo. Así leo también los desafíos siempre atentos a una disidencia que no puede estar segura de sí misma, ni de su activismo en tanto su colectividad no cuestione de antemano los axiomas de la identidad y la política como la reconocemos hasta hoy.

\section{REFERENCIAS BIBLIOGRÁFICAS}

Castillo, Alejandra (2011): Nudos Feministas: Política, filosofía, democracia. 1 edición. Santiago: Editorial Palinodia. 108 pp.

(2007): Julieta Kirkwood políticas del nombre propio. 1 edición. Santiago: Editorial Palinodia. 97 pp. 
Kirkwood, Julieta (1990): Ser Política en Chile. Los nudos de la sabiduría feminista. 2 edición. Santiago: Editorial Cuarto Propio. 255 pp.

Richard, Nelly (2008): Feminismo, género y diferencia(s). 1 edición. Santiago: Editorial Palinodia. $117 \mathrm{pp}$.

Thayer, Willy (2011): El barniz del esqueleto. 1 edición. Santiago: Editorial Palinodia. 73 ppdd. 